\title{
Quantifying the Climatic and Anthropogenic Impacts on Streamflow in the Different Reaches of Wei River, China
}

\author{
Changxue $\mathrm{Wu}^{1}$, Jian $\mathrm{Xie}^{1}$, dexun $\mathrm{Qiu}^{2}$, Zhibo $\mathrm{Xie}^{1}$, Peng $\mathrm{Gao}^{1}$, and Xingmin $\mathrm{Mu}^{1}$ \\ ${ }^{1}$ Institute of Soil and Water Conservation Northwest A \& F University \\ ${ }^{2}$ Institute of Soil and Water Conservation Chinese Academy of Sciences and Ministry of \\ Water Resources
}

May 10, 2021

\begin{abstract}
Wei River is the largest tributary of the Yellow River, and in recent decades, water resource has changed significantly. Identifying the characteristics and influencing factors of streamflow change in Wei River is needed for development of effective management strategies and economic development for the region and entire Yellow River basin. The analyzations were based on streamflow records from 1957 to 2018 at five hydrological stations as well as precipitation and air temperature data from 22 meteorological stations. Mann-Kendall method and Pettitt test were used to analyze trends and transition years of hydrometeorological variables. Double mass curves (DMC) were used to quantify the impact of climate changes and anthropogenic activities on streamflow change. The results showed that: the annual average streamflow decreased significantly in the upper reaches (URWR), middle reaches (MRWR) of the main Wei River, Jing River Basin (JRB), Beiluo River Basin (BLRB) as well as the whole Wei River Basin (WWRB). There were transition years existed in these reaches and concentrated in 1990s. The annual precipitation showed a significant downward trend in the MRWR, LRWR, BLRB and WWRB $(\mathrm{P}<0.01)$. Air temperature in all reaches rise significantly $(\mathrm{P}<0.01)$. Analysis of land use from 1980 to 2020 indicated that residential land and grassland increased markedly. The results of DMC showed that anthropogenic activities were the dominant factors for streamflow reduction, accounting for $52.96 \%-92.2 \%$. For different reaches, the intensity of human activities (domestic water, agricultural irrigation, industrial water, soil and water conservation measures and reservoirs construction, etc.) was different, resulting in the difference of contribution rate. Relevant research results provide basis for scientific regulation of water resources in Wei River Basin.
\end{abstract}

\section{Hosted file}

main document.pdf available at https://authorea.com/users/412991/articles/521466-quantifyingthe-climatic-and-anthropogenic-impacts-on-streamflow-in-the-different-reaches-of-weiriver-china

\section{Hosted file}

Table 1-5.pdf available at https://authorea.com/users/412991/articles/521466-quantifyingthe-climatic-and-anthropogenic-impacts-on-streamflow-in-the-different-reaches-of-weiriver-china 


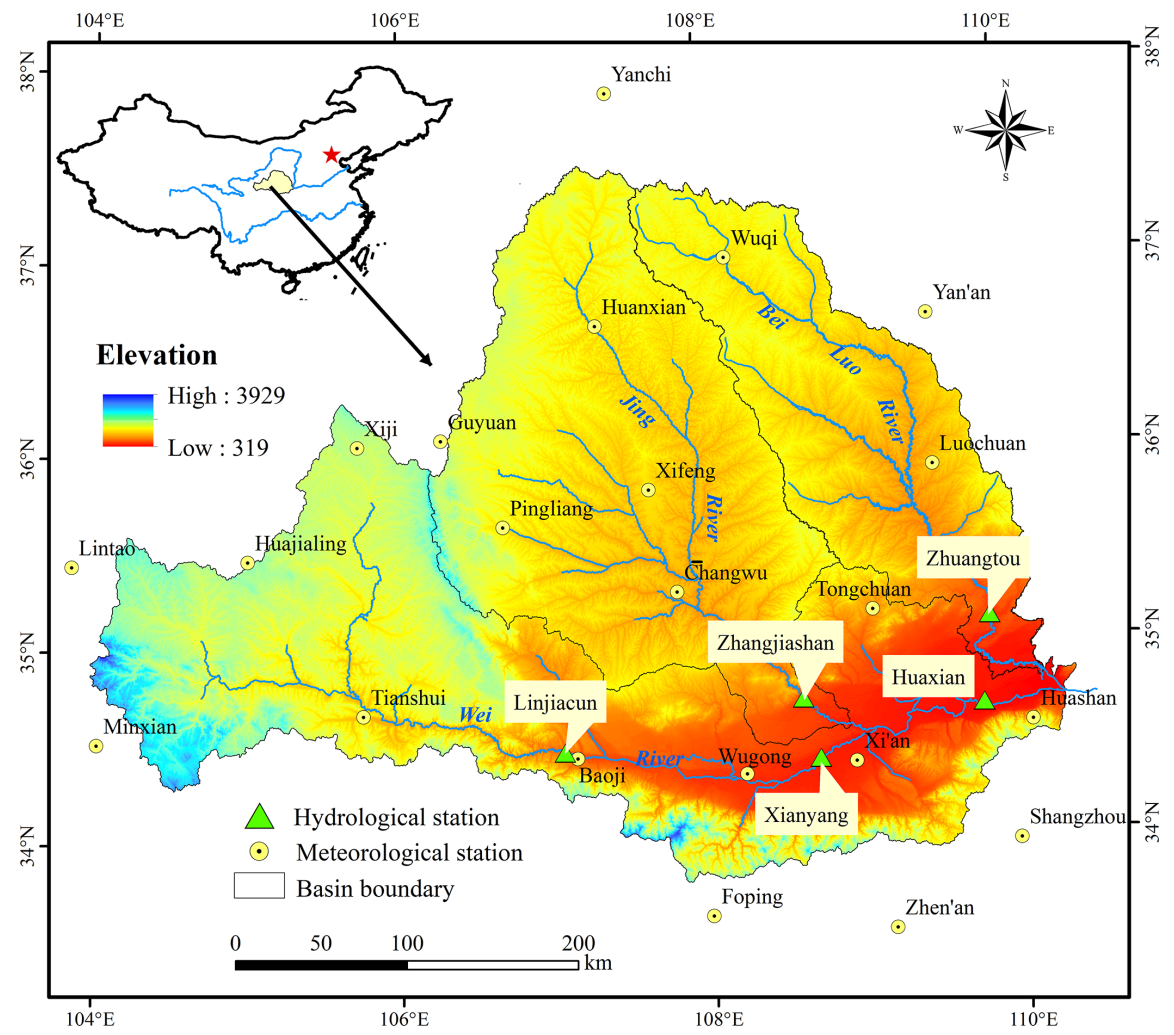



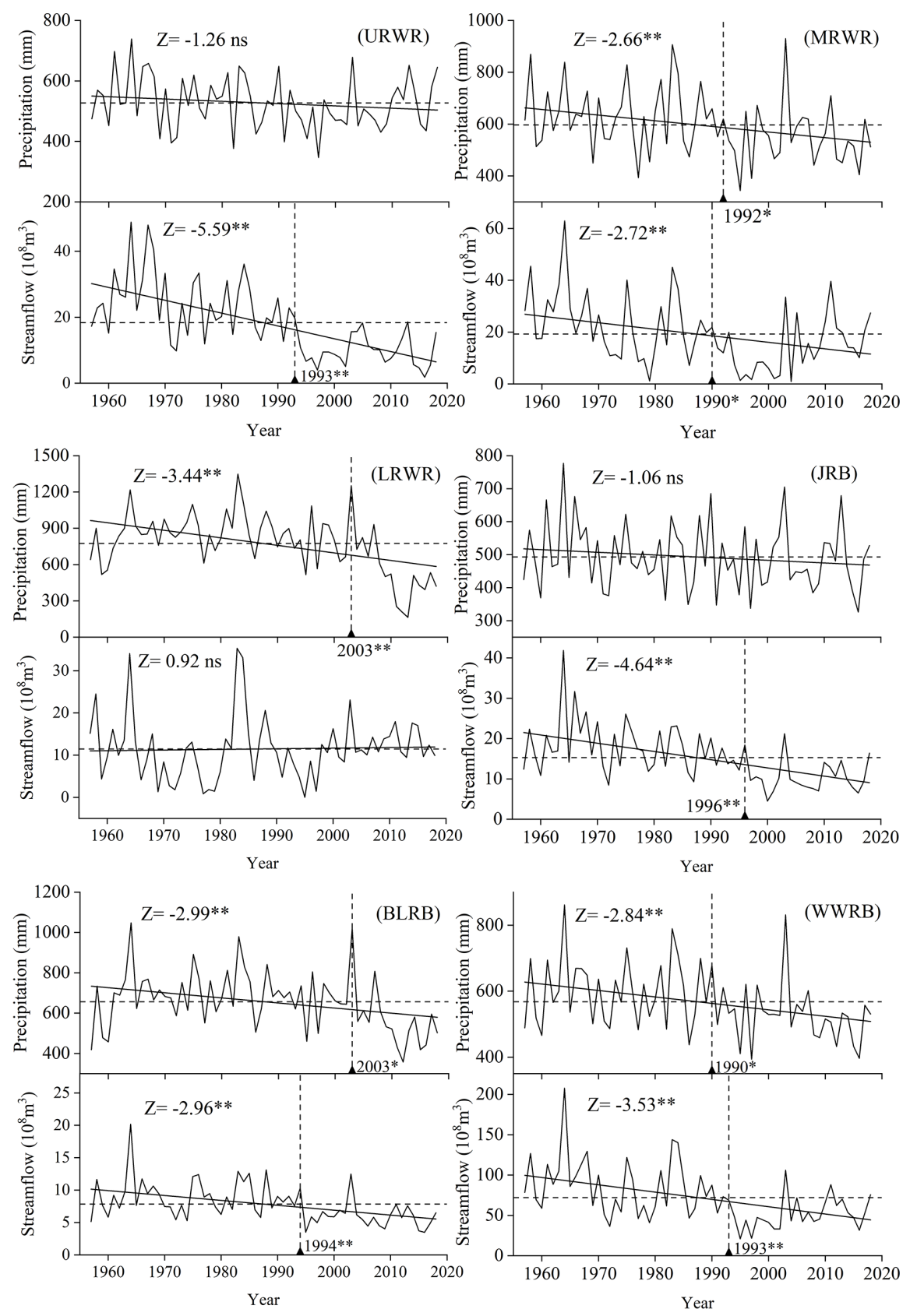

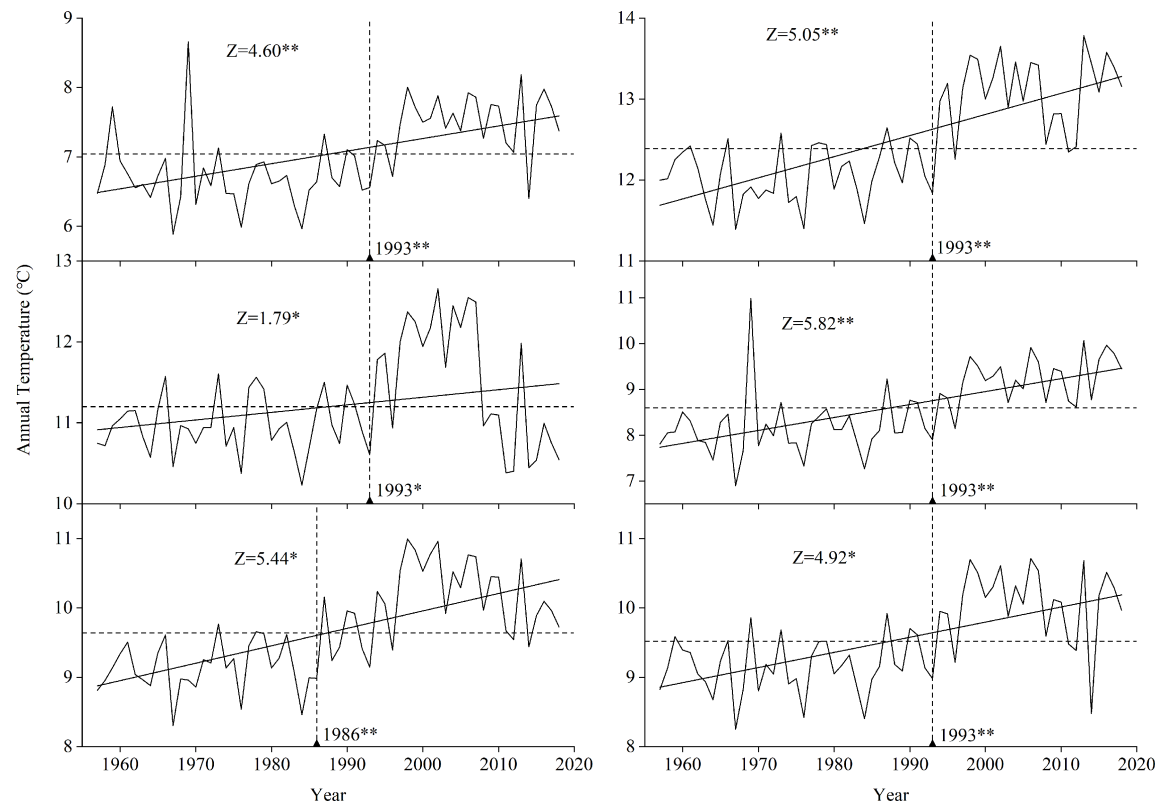


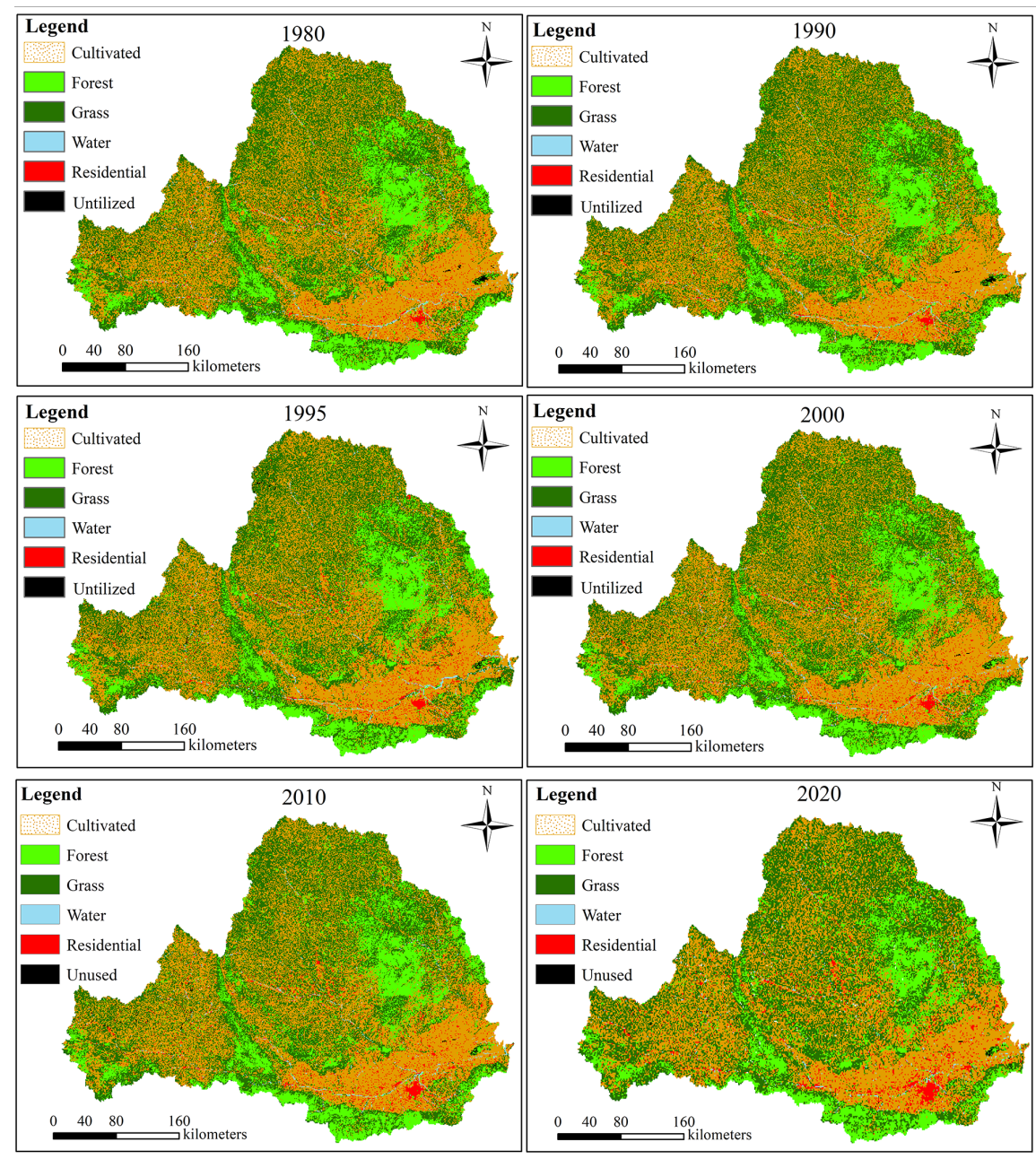



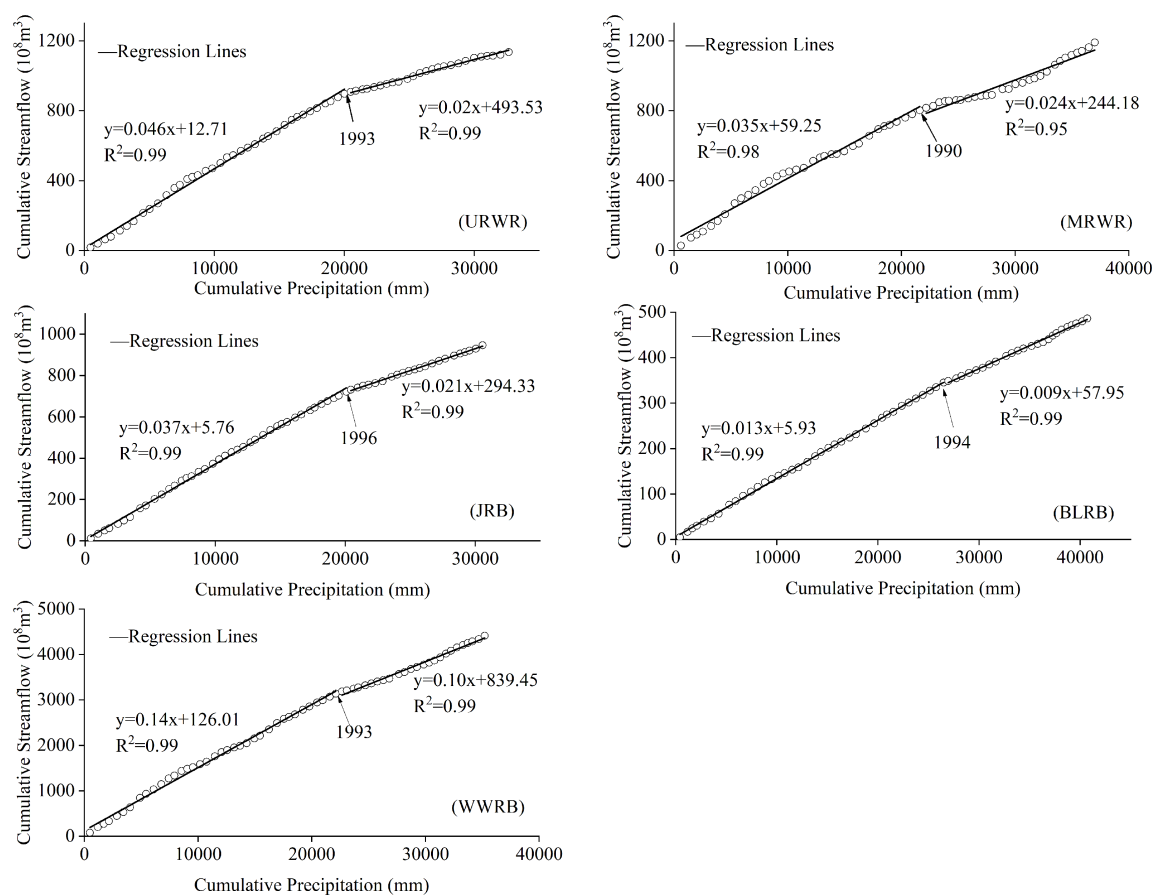

6 